\title{
A REAL OPTIONS APPROACH TO DESIGN FOR \\ QUALITY STANDARDS CONSIDERING LIFE CYCLE OF A PRODUCT
}

by

\author{
Aasyfa Mullick \\ B. Eng (Textile Engineering) \\ National Textile University, \\ Faisalabad, Pakistan, December 2008 \\ An MRP \\ presented to Ryerson University \\ in partial fulfillment of the \\ requirements for the degree of \\ Master of Engineering \\ in the program of \\ Mechanical and Industrial Engineering
}

Toronto, Ontario, Canada, 2016

(c) Aasyfa Mullick 2016 


\section{AUTHOR'S DECLARATION}

I hereby declare that I am the sole author of this MRP. This is a true copy of the MRP, including any required final revisions.

I authorize Ryerson University to lend this MRP to other institutions or individuals for the purpose of scholarly research

I further authorize Ryerson University to reproduce this MRP by photocopying or by other means, in total or in part, at the request of other institutions or individuals for the purpose of scholarly research.

I understand that my MRP may be made electronically available to the public. 


\title{
A Real Options Approach to Design for Quality Standards Considering Life Cycle of a Product
}

\author{
Aasyfa Mullick \\ Master of Engineering, Industrial Engineering, 2016 \\ Ryerson University
}

\section{Abstract}

Flexibility is recognized as a valuable parameter for a manufacturing system. When valuing flexibility for quality standards of a production facility, there must be a tool to precisely justify the value delivered by the preferred standards. In this project, we have developed an options model that accounts for the demand dynamics during the product life cycle. We consider a manufacturing facility that employs a specific quality control chart. A second control chart with more strict standards is generated and the effectiveness of two control charts is analyzed with options framework considering the life cycle of the product. The options model is evaluated by lattice approach and the dynamic programming model. The results show that a set of appropriate levels of quality standards when adopted by a manufacturing system can be profitable for the firm. 


\section{Acknowledgements}

I am very grateful to my project supervisor, Dr. Mohamed Wahab Mohamed Ismail, for his motivation and continuous support for this project. His immense knowledge and guidance has greatly helped me during the preparation and writing of this report. I wish him the very best in his future endeavours. 


\section{Table of Contents}

Author's Declaration $\quad$ ii

Abstract $\quad$ iii

Acknowledgements $\quad$ iv

Table of Contents $\quad$ v

List of Tables $\quad$ vii

List of Figures

List of Notations $\quad$ ix

1 Introduction $\quad 1$

2 Literature Review $\quad 6$

2.1 Quality Control 6

$\begin{array}{ll}\text { 2.1.1 Quality Costs } & 7\end{array}$

2.1.2 Quality Control Charts 8

2.2 Product Demand 10

$\begin{array}{lll}\text { 2.2.1 Product Life Cycle } & 10\end{array}$

2.2.2 The Significance of Product Life Cycle 12

$\begin{array}{lll}\text { 2.2.3 Demand Dynamics } & 14\end{array}$

$\begin{array}{lll}2.2 .4 & \text { Regime Switching } & 15\end{array}$

2.3 Product Pricing 16

$\begin{array}{ll}\text { 2.3.1 Skimming Price } & 17\end{array}$

$\begin{array}{ll}\text { 2.3.2 Penetration Price } & 18\end{array}$ 
2.4.1 Black Scholes Formula

2.4.2 Monte Carlo Simulation

3 Modeling Section

3.1 Applying Financial Models for Quality Control

3.2 Demand and Price Correlation

3.3 Lattice Construction

3.4 Valuation of the Project

4 Numerical Section

4.1 Findings of the Study

4.2 Results 


\section{List of Tables}

Table $1 \quad$ Suitable option valuation methods for option types and number of variables 21

$\begin{array}{lll}\text { Table } 2 & \text { The demand regimes } & 29\end{array}$

$\begin{array}{lll}\text { Table } 3 \quad \text { Correlation between demands } & 30\end{array}$ 


\section{List of Figures}

Figure 1 Relation between variables, option value, control charts effects and the $\begin{array}{ll}\text { decision } & 26\end{array}$

$\begin{array}{lll}\text { Figure } 2 & \text { The demand regimes in relation with price } & 29\end{array}$

Figure $2 \quad$ Mean of growth regime versus profit gain 34

Figure $3 \quad$ Mean of decay regime versus profit gain 34

Figure $4 \quad$ Mean of price versus profit gain 34

Figure $5 \quad$ Volatility of growth regime versus profit gain 34

Figure $6 \quad$ Volatility of decay regime versus profit gain 35

Figure $7 \quad$ Volatility of priceversus profit gain 35

Figure $8 \quad$ Correlation factor of decay and priceversus profit gain 35

Figure $9 \quad$ Correlation factor of growth and price versus profit gain 35

Figure $10 \quad$ Product demand versus profit gain 36

Figure 11 Product price versus profit gain 36

Figure $12 \quad$ Defect rates $g_{1}$ and $g_{2}$ versus profit gain 36

Figure $13 \quad$ Fixed costs $\mathrm{K}_{1}$ and $\mathrm{K}_{2}$ versus profit gain 36 


\title{
List of Notations
}

\author{
$S \quad$ Spot price of the underlying asset(for a European call option) \\ $T \quad$ Time till expiry of the European option \\ $t_{E} \quad$ Purchase time of the European option \\ $C_{E} \quad$ Value of European call option \\ $P_{E} \quad$ Value of European put option \\ N(.) Cumulative distribution function of the standard normal distribution \\ $K_{e} \quad$ Exercise price of the option \\ $\sigma_{e} \quad$ Volatility of returns of the underlying asset \\ $r \quad$ Risk free rate \\ $X \quad$ Underlying variable in a risk neutral world \\ $\Delta t \quad$ Length of time interval \\ $\varepsilon \quad$ The random sample taken from a normal distribution \\ $\rho_{v} \quad$ Co-efficient of variation \\ $R(t) \quad$ Sales revenue of a product for a time period that begins at time $t$ \\ $S_{1}(t) \quad$ Number of sales of a product for a time period that begins at time $\mathrm{t}$ \\ $S_{2} \quad$ Product price \\ F $\quad$ Fixed production cost for a time period \\ $V \quad$ Variable production cost per unit of the product \\ $P(t) \quad$ Total profit for a time period that begins at time $\mathrm{t}$ \\ $S_{2}(t) \quad$ Product price for during a time period that begins at time $\mathrm{t}$
}




$\begin{array}{ll}\Gamma(t) & \text { Total profit for a time period t } \\ g_{1} & \text { Loss that results from applying control chart 1 (defect rate) } \\ g_{2} & \text { Loss that results from applying control chart 2 (defect rate) } \\ K_{1} & \text { Fixed cost of using control chart 1 } \\ K_{2} & \text { Fixed cost of using control chart 2 } \\ V_{1} & \text { Variable cost of using control chart 1 } \\ V_{2} & \text { Variable cost of using control chart 2 } \\ A_{g} & \text { Growth regime of demand } \\ A_{d} & \text { Decay regime of demand } \\ B & \text { Price (as a representation of correlation with demand regimes) } \\ \mu_{g} & \text { Mean of growth regime } \\ \sigma_{g} & \text { Volatility (standard deviation) of growth regime } \\ \mu_{d} & \text { Meanof decay regime } \\ \sigma_{d} & \text { Volatility of decay regime } \\ \mu_{d} & \text { Mean of price } \\ \sigma_{d} & \text { Volatility of price } \\ \rho_{1} & \text { Correlation factor for growth and price } \\ \rho_{2} & \text { Correlation factor for decay and price } \\ \omega & \text { Thener process }\end{array}$


$P$

$p^{i}(t)$

$\pi_{t}$
Combined regime

The probability of a product $i$ for switching from growth to decay at time $t$

Optimal profit by the product in period $t$ 


\section{Chapter 1}

\section{Introduction}

When a manufacturing facility invests to improve the quality of their goods, the decision makers ought to be aware of the value that this investment will deliver to the firm. They need to know how much investment in quality is reasonable and what level of quality is enough (Mihalcin et. al. 2014). A system to validate and maintain a desired level of quality in a product or service by planning, inspection and taking necessary corrective measures is known as quality control (Milo et. al. 2015). Quality control is important in the success of a business that aims to deliver products that would meet or go above the customers' expectations. When a market is supplied with quality products, the customer satisfaction increases and vendor customer relationship is strengthened.

The quality control department of a firm takes required action to monitor the process and product so that they comply with a set of defined quality standards (Kale 2014). In some cases, the profits may not offset the costs of achieving the defined quality standards and the company may need to switch the quality standards to less strict levels. The ability to switch between two prospective quality standards is an example of real options for management and decision making (Nicholls et. al. 2014). The real options can enhance a project value by 
enabling the managers to generate more effective production and can be computed with financial engineering techniques (Nembhard et. al. 2002). The options model for manufacturing systems considers the demand variability during life cycle of a product.

A number of real options have been exercised in production management using financial option valuation methods. The options valuation in manufacturing systems has been one of the major domains of research. For example, the capacity choice and capacity expansion (Pindyck 1988) and (He and Pindyck 1992), optimal times of investment in an irreversible project (McDonald and Siegel 1986) and the variability in the output mix in a flexible production system (Triantis and Hodder 1990). Although there is an extensive literature on valuing different flexibilities with a real options approach, the uncertainty in demand is generally modeled using a Geometric Brownian motion (GBM). The GBM when used for the demand regime accounts for the continuous growth of demand without considering the fact that the demand for a product grows primarily, then becomes stable for a period of time and finally falls off. This implies that the demand growth varies throughout the product's life and cannot be precisely analyzed by simple stochastic processes. Numerous product categories ranging from high technology goods like semiconductors to automobiles follow well-defined product life cycle patterns (Bass 1969). These products generally follow the bell shaped sales pattern and their demand dynamics generate considerable managerial challenges (Birou 1998).

A study on 143 firms in manufacturing and services sector shows that when these firms switched from their current quality management systems (QMS) to ISO 9000 quality systems, the effects of this change on the performance and profitability of the firm was not considerable 
for a duration of 5 to 6 years after implementation of the new system (Tsekouras et. al. 2002). The revelation of these facts generate a call for the promotion of quality standards towards more targeted policies so that the strategic effects of adoption of new quality control systems can be acknowledged. A research to observe the grounds for creating a new QMS (ISO 9001:2000) revealed an improvement in the business performance (White et. al. 2009). However, these effects were noted on the conceptual grounds and the authors state that the value of this QMS as a symbol of 'quality' within the organisation has yet to be fully assessed.

In the automobile sector, a company must recall the sold vehicles for repairs and/or compensation in case there arises any serious problem with the vehicle model. For example, in September 2014, Ford was known to recall around 850,000 cars and SUVs due to a malfunctioning that may hold back the airbags from working during a crash. The company declared that the dealerships will change the restraints control module free of cost (The Associated Press 2014). The restoration costs are acknowledged by the company, however if the ensuing problems in the model were identified by the QMS of the production facility, the corresponding adjustments would have been more convenient and applied at considerably lower costs. These setbacks bring about the need for an efficient quality control system. The motivation for better quality standards can be created when the firm is able to justify the effectiveness of new prospective quality schemes in relation to the existing schemes.

The valuation design of real options for quality control charts presented in Nembhard (et. al. 2002) considers the manufacturing decision of either introducing a control chart to observe quality or continuing to manufacture goods without quality control. However, in the present 
world where consumers have an increased awareness of product quality and the market competition is growing day by day, the survival of an organization without a QMS is at a high risk. Hence, an options model has been created in this report to select from one of the two prospective quality control standards.

In this report, a real options approach has been employed to value the profit gain of switching from an existing level of quality standards to relatively more strict standards that will be applied if profitable. To justify our preferences, there must be a tool required to measure the effectiveness of one quality control chart over the other. So the resulting defect rates of the manufacturing facility were studied after applying each potential control chart. These defect rates reveal the consequent losses from using each control chart and help to precisely judge the relevant profitability of one quality control scheme over the other. The problem is solved by a three dimensional lattice approach that incorporates the behaviour of product life cycle and price uncertainty of the product. A sensitivity analysis was executed to show the effects of each variable on the consequential relevant profitability. The results of this study and the corresponding sensitivity analysis would help the decision makers to make the better choice as they could find answers to their queries about the value of applying the preferable quality control scheme.

This report is organized as follows: Chapter 2 reflects on the relevant domains of study in the existing literature that includes the concepts of quality control, product demand, product life cycle, regime switching, product pricing, options valuation and existing methods for valuation. Chapter 3 develops the financial model and describes the lattice framework and the 
dynamic programming model. Chapter 4 introduces a numerical example to illustrate the values of flexibilities and Chapter 5 concludes the paper. 


\section{Chapter 2}

\section{Literature Review}

\subsection{Quality Control}

Quality control (QC) is a process or a collection of processes determined to verify that a certain product or service complies with a specific set of quality standards or abide by the customer requirements (Kale 2014). A quality control system comprises of predefined rules and standard procedures for a business with the aim of keeping the corresponding product, process or service up to the mark (Milo et. al. 2015). QC is similar to quality assurance (QA) with some variation. Quality assurance is the process employed by the industry to administer and review the quality control system. QA consistently monitors to assure that the system complies with the defined set of quality standards (Rothery 1992).

The successful businesses highly emphasize the implementation and execution of QC procedures and deliberately planned measures are taken to make sure that their products and/or services are constantly reliable and meet the requirements of their prospects (Mihalcin et. al. 2014). These quality management practices guarantee superior quality products and services (Tsekouras et. al.2002). The quality of a product can be assessed as regards its 
performance and reliability. It is an essential parameter that distinguishes a firm from its competitors. The effective quality management in an organization leads to customer satisfaction that results in customer loyalty (Vloeberghs and Bellens, 1996). It is very important for the prosperity of an organization to have a number of loyal customers, and the customers are obliged in case when the products meet their expectations (Milo et. al. 2015).

The effective QC procedures ensure larger revenues and high productivity for the firm (White et. al. 2009). The efficiency of quality system can be raised by implementation of innovative and efficient techniques and removal of unnecessary processes that are a mere waste of employees' time and do not contribute much to the productivity of the organization. Any serious efforts in terms of quality improvement must consider the costs related to the upgrading of quality as the aim of consistent development programs is not just to fulfill the buyer requisites but even achieve this objective at the minimum cost (Schiffauerova and Thomson 2006). This can be done only by diminishing the expenditures required to attain quality and these expenses can be reduced only when they are acknowledged and measured.

\subsubsection{Quality Costs}

In the process improvement efforts in an organization, the costs of quality are the total costs required to execute the quality improvement efforts and overcome deficiencies (Feigenbaum 1956). Before this concept was introduced, the common understanding was that it needs more costs to achieve higher standards of quality and involves better raw materials, machines or hiring of more labour. Further, as cost accounting emerged to categorize financial transactions of shareholders, it did not classify the quality related costs. This is very important as when the 
quality related entries are categorized from the general ledger of a company, the management is able to assess the investments in its QMS in terms of cost reduction and gain in profitability.

The concept of improvement in quality control system proposes that the higher investments in effective quality systems result in much higher savings that may otherwise be spent in quality related failures and evaluation efforts. The organization should validate this phenomenon for itself (Feigenbaum 1956). When the manufacturing organizations come across increasing number of defects, they generally react by increasing the number of employees in inspection procedures. However, the inspection cannot be absolutely efficient so the quality assessment costs remain high when the failure costs are high. Hence the single promising solution of this problem is to establish the sufficient levels of prevention from occurrence of faults. When the quality costs are categorized, they can be helpful to calculate, examine, plan and forecast. The reporting should be done by accounting department to guarantee the justice of results. Moreover, the total cost of quality will be more comprehensive for wider audience if it is expressed as a percentage of sales, manufacturing cost, sales cost or the operations cost for service industry.

\subsubsection{Quality Control Charts}

When the quality of products is concerned, the quality control charts help to maintain a process in statistical control. The reasons for processes to get out of control can be classified as common reasons and special reasons (Deming 1986). Common reasons are related to the normal constant flow of the process while it is in a controlled form. The special reasons can be referred to as the issues that emerge at regular intervals in an unforeseeable way. The control 
charts help to locate and remove special reasons so that the process can be adjusted to the target level (Mihalcin et. al. 2014).

Without the use of a control chart, the manufacturer cannot realize the quality levels of his produced goods (Milo et. al. 2015). In such case, the inferior goods may be identified at the final inspection and scrapped. However, if the defective or inferior products reach the endusers, they might be returned and the firm will gain a reputation of inferior quality. This will probably result in reduction of demand and loss of market share. The firm will finally have to pay for not employing the control charts for statistical process control (Nembhard et. al. 2002). The use of control charts involves a certain cost as well; to maintain the quality standards of processes and produced goods. The fixed costs include equipment installation and the recurring costs comprise of operator wages, sampling, etc. depending upon the nature of products. A manufacturer can select from a range of quality standards that his firm can follow to achieve the target quality of their final products. These standards can be less strict or very strict depending upon the manufacturer's preferences. The cost of implementation of more strict quality standards is probably higher than that of less strict standards, yet it pays back in the long run as regards the product demand, customer satisfaction and firm's reputation are concerned. However, there must be some means of evaluating the appropriate level of quality standards that must be employed by a firm to achieve the optimum results; and this concept is the basis of our study. 


\subsection{Product Demand}

The amount of a product or service that the consumer(s) will want to purchase at a given price is known as demand. Alongside the supply phenomenon, demand is one of the two basic determinants of price. The product demand is determined by many factors including the price, price of substitute goods, and similar goods. With the availability of these alternate choices, the demand of a product continues to vary during the time span of its existence in the market, referred to as product life cycle (Gherasim 2011).

Prior to further discussion on demand dynamics, here is a review of the product life cycle concept and its significance.

\subsubsection{Product Life Cycle}

When a new product is launched in the market, it undergoes a series of stages from introduction to development, then maturity and finally decline (Orbach and Fruchter 2014). The time period starting from the birth of a product to the moment when it is removed from the market is known as product life cycle (PLC).

The PLC concept reveals the idea that a product has a limited life time. The product demand and corresponding sales follow certain stages through its life span and yield different profit

levels at each stage (McCarthy, et. al. 1994a). This creates a need for implementation of different marketing strategies to create a harmony between product demand and supply. The PLC stages are described below with examples from consumer electronics sector. 
When a new product enters the market, it starts off with low sales and typically high advertising costs so that the customer awareness of the product is rapidly increased (Tyagi et. al. 2015). During this stage, the additional costs are likely to be applied for the distribution of the product which is at the initial stage of introduction. These high costs alongside low sales volumes generally result in losses. However, during the introduction stage, the main objective is to set up a market share and motivate an initial demand for the product (Thimm et. al. 2006). For example, 3D televisions are in the market for a few decades; however, it has been due to a substantial investment by media companies that 3D TVs are available for home use. They are a good example of a product in the introduction stage.

The development stage refers to market penetration followed by a rapid revenue growth. The increase in number of prospects becoming aware of the product and its benefits result in increased sales. When the product proves to be successful, its demand is elevated with the further growth of sales (Orbach and Fruchter 2014). The product distribution can be expanded at this level. The competitors may enter the market during the development stage. This is compensated by price competition or higher promotional costs to acquire the maximum market share. The Blue Ray players are high-tech equipment that delivers an excellent viewing experience. This product currently has a steady increase in sales which is the characteristic of development or growth stage.

Maturity is represented by a slowdown in the growth of sales. The product achieves substantial awareness by this time and advertising costs are reduced. If competitive products appear in the market, either the price of the product or market share has to be reduced. In this 
case, the firm makes efforts to persuade the competitor's customers to shift, and transform non-users into customers. The retailers can be encouraged with sales promotions to allocate more shelf space to the product in contrast with competing products. The primary target during the maturity stage is to hold the market share and lengthen the product life cycle (Sommers et. al. 1998a). This stage generally persists longer than the previous stages. It can be referred to as the case of DVD players that were introduced several years ago. The manufactures of DVD players and the associated equipment have achieved a significant market share. However, they are facing challenges with products from other technologies. This feature represents the maturity stage.

When the market becomes saturated, new competitive products start replacing the existing product. This results in decline of product sales (Lambertini and Mantovani 2010). At this stage the overall profit from the product will start to decrease. The unit costs increase due to declining production quantities and finally, no more profit can be made. For example, the VCRs are still available in the market; however this is a product in its decline stage. The products of newer technologies have acquired the attention of consumers for their versatility, convenience and lower prices.

\subsubsection{The Significance of Product Life Cycle}

Since the introduction of PLC phenomenon in 1950, the PLC theory has achieved considerable acknowledgement as a means for creation and implementation of effective marketing strategies. The PLC was found on the idea that a product passes through a life cycle similar to humans (birth, adolescence, middle age/maturity, death) (Birou et. al. 1998). This 
perspective helps to somehow forecast a model of the lifespan of a product and provides guideline for the necessary efforts in the production and delivery of the products. The PLC concept is thus considered a unique tool for the strategic decision making of the company as the efforts made at every step help to achieve company goals (Mohammadi et. al. 2014).

The PLC is a very significant concept in marketing for three main reasons (Golder and Tellis 2004). First, the managers experience varying levels of pressures before and after entering the new stage in the product life cycle. The introduction stage brings about a fear of gloom and an increasing pressure on managers to maximize their efforts for the breakthrough of new products in the market. The growth stage comes up with hopefulness and the managers are enthusiastic to meet the growing demand. Thus, the prediction of start and end points of each stage also known as turning points help to maintain a balance in demand and timely supply. Secondly, the sales and its decline or ascent considerably varies along the stages of the life cycle. The acknowledgment of these expected changes is a great help for managers to plan the corresponding production levels, distribution, marketing and advertising. Third, the product costs and prices are affected by the variation in production levels (Tyagi et. al. 2015). Prices decline during the product life cycle significantly during the early stages and the customer's concern for price increases over the life cycle stages. The sales patterns should thus be studied and considered before strategic planning (Orbach and Fruchter 2014).

The PLC serves as a very good basis upon which the strategic plans for new products/services can be built (Mohammadi et. al. 2014). It is a simple concept, has an excellent track record, perceptive appeal and a general acceptance. Using the PLC as a structure on which a model 
can be built is significant for many reasons (Birou, Fawcett and Magnan 1998). The importance of PLC concept can be judged by the fact that it can lead to the lucrative product management as it enables the management to optimize the strategy and develop tactics that directly influence the product policy (Onkvisit and Shaw 1986).

\subsubsection{Demand Dynamics}

When a single demand parameter is employed in a study that deals with the demand of a product throughout its life cycle, it will ignore the possibility that the demand varies during the time span of the life of product. Hence a product life cycle model should be based on the fact that demand would decline at some level because of competing goods, superior technology goods, market saturation or change in consumers’ preferences (Bollen 1999).

The product demand, in the real options literature, is generally assumed as an underlying stochastic variable regulated by a geometric diffusion. The geometric diffusion is workable but it has a few undesired effects. When the rate of growth of demand is monitored with the geometric diffusion, this shows that the demand will continually grow at a steady rate. This sounds unreal because it overlooks the possibility that the demand of the product will change in a specific way during the product life cycle. So the product life cycle models account for the fact that demand will decline at certain level because of particular reasons. A study shows that the diffusion model implies an exponential growth in sales to a level that creates a peak followed by an exponential decay (Bass 1969). The product life cycle models may be considered as the regime-switching models that involve different stochastic demand schedules 
for each stage in the product's life. Moreover, the time-span of every phase of the product life cycle is indefinite.

When a product life cycle accounts for the demand dynamics of the product, it may result in a considerable valuation error in case a single demand schedule is employed with a simple specification (Huang 2009). If the demand is assumed to be continually growing, it naturally underestimates the option to shrink or give up the project because it undervalues the possibility of less demand in future. Similarly, the idea of consistent and steady growth will overvalue the option of expansion of the project as it expects the demand to increase perpetually. The real options and demand schedules of product life cycle that depends on regimes make the justifications of this hypothesis seem ambiguous.

\subsubsection{Regime Switching}

Regime switching is a significant approach to model time dependent non-linear equations to presume varying behaviour (structural break) ranging from one subsample to the other. The subsample is referred to as a regime. Since the demand comes across a continual variation throughout the product life cycle, the consequent number of sales has two regimes; the growth regime and the decay regime characterized by time t. The combined regimes are a grouping of each of the growth and decay regimes with price: demand growth with price and demand decay with price. The two groups of combined regimes employ correlation coefficients and a regime switching cumulative normal distribution. 
The geometric Brownian motion (GBM) has been used to model the regime switching approach. GBM is a continuous-time probabilistic procedure represented by the log of a quantity that changes randomly and follows a Brownian motion with flow. This is also known as a Weiner process. The geometric Brownian motion is a significant example of a stochastic process that satisfies a stochastic differential equation. In this paper, both the number of sales and the price follow a geometric Brownian motion.

\subsection{Product Pricing}

When the product life cycle is under consideration, a suitable pricing policy plays a vital role to maximize the profitability of the product. It can help to enter a new market, increase market share of the established market and defend the existing market share from the new competitive products (Yeoman 2007). A business may prosper by either lowering or raising product prices, depending on the needs and buying behaviours of customers in a specific market. The identification of a suitable pricing strategy is an important factor in operating a successful business.

The pricing of a new product is generally a choice between one of the two basic pricing policies; skimming price and penetration price. The actual range of pricing strategies is much wider than this and a keen analysis of the situation identifies the issues for consideration (Chenavaz 2012). 


\subsubsection{Skimming Price}

Skimming price is a policy that involves high introductory prices aimed to skim the cream of demand. The price is deliberately lowered as the product enters the maturity stage (McCarthy et. al. 1994b). There are many reasons for the success of this policy. In the early stages, the demand is probably less elastic because consumers take time to understand its value in comparison with the value of current alternatives. This is especially true for consumers' goods. An innovative product like an electric blanket was not welcomed at the beginning as part of a buying motive. Furthermore, the product did not face much competition at the beginning and this resulted in a low cross-elasticity of demand.

When a product is launched with a high price, it renders efficient in dividing the market in segments that have the different price elasticity of demand. The high price at the beginning skim the cream of the market; buyers that are comparatively unconcerned about the price (Chenavaz 2012). The successive reductions in the price take over more elastic sectors of the market. The organized sequence of editions of a book is a good example of this pricing strategy that initiates with a very expensive personal edition and ends up with a lower priced paperback. Most of the companies are not in a position to invest in new products that come up with significant revenues in prolonged time spans. High cash returns in the initial stages compensate for high production, distribution and organizational costs in creating the pioneer product (Sommers et. al. 1998b). The high prices render a significant financing technique to sustain these burdens keeping in view the uncertainties of the future. 
The skimming price policy is considered as a relatively safe one. Since a new product comes across an unknown elasticity of demand, a high introductory price acts as a 'refusal' price during the stage of exploring the market. It is hard to forecast the reduction in price with market expansion and as the design of the product is improved by increase in production efficiency (Johansson et. al. 2011). Once a new lamp bulb was introduced by an electrical company at a relatively high introductory price, an announcement was also made that the price would be reduced as soon as the company would come across ways of its cost reduction. The passive approach of skimming policy has the advantage of conservation of some profits at all stages of product life cycle. However, it is unable to capture the market share of many buyers who have low income or low preference and are reluctant to pay a considerable premium for the product or prestige superiority (Yeoman 2007). Furthermore, it encourages the entry of competitors as they notice high margins available in the industry. The price skimming policy is effective when the firm is facing an inelastic demand curve.

\subsubsection{Penetration Price}

The policy to use low prices that serve as an active means for market penetration at the beginning is known as penetration price. This policy is the reversion of skimming policy where the price is reduced only when the market competition implies. This approach is considered wise when the amount of buyers that are willing to pay a high price is small. The penetration pricing can create goodwill among the early adopters and enable further adoption by word of mouth. The low product prices discourage the entry of competitors (Dolgui and Proth 2010). This policy is appropriate for a product suitable for mass market and where the 
product demand is highly price elastic. Penetration price can be based on the economically efficient phenomenon of marginal cost pricing.

The penetration pricing results in expectations about the product to maintain a consistently low price. This creates difficulties in ultimately raising the prices. Some researchers argue that generally, the bargain seekers are attracted by penetration pricing who move on to other products with the rise in prices. This has been a controversial issue for many years as if it is more beneficial to increase prices slowly or apply a one-step large price increase. Another potential limitation of this policy is that the low profit margins are not feasible for long to bring about success of the strategy.

In this study, the price is modelled in relation with the number of sales, effect of quality control chart, profits and the options value. The price and the number of sales are variables and their variability is related to the product life cycle.

\subsection{Options Valuation}

An option is an agreement that confers the right to the buyer for buying or selling an asset at a particular price at or prior to a specific date, depending on the type of the option. The buyer has a right and not the obligation, however, the seller has the subsequent obligation to carry out the transaction; either sell or buy, in case the buyer would exercise the option (Nicholls et. al. 2014). Fundamentally, there are two types of options known as calls and puts. A call option confers a right to the buyer of option to purchase an asset until a specific date at a particular 
price. A put option provides the buyer a right for selling an asset until a specific date for a particular price (Hull 2005). The price of the options contract is called the option premium and the date of the contract is referred to as expiration date. An option can be either European or American. An American option can be exercised at any time through its lifespan but the European option can be exercised on the expiration date only.

The manufacturing systems mostly have numerous sources of uncertainty. These uncertainties can be managed by analyzing them as multiple state variables (Wagner et. al. 2014). Real options valuation techniques can be employed according to the range of problem variables and the option type (Nicholls et. al. 2014).

When the problem has a single variable, the binomial lattice technique of Cox, Ross and Robinstein (CRR) may be used for valuation of European and American options (Cox, Ross and Robinstein 1979). The Black-Scholes method (Black and Scholes 1973) is designed for valuation of a European option for a single variable. The Black Scholes method provides a closed form solution for the option and gives accurate results. However, the results by a binomial lattice are an approximation that will converge to Black Scholes valuation with the increase in number of steps in the lattice. In order to solve the problem with two state variables, Boyle (1988) added an extension to the CRR method. Later, an n-state variable extension of the CRR procedure was developed in Boyle (et. al. 1989). Kamrad and Ritchken (1991) created a similar method for valuing options for single or more state variables. This technique uses a pentanomial lattice for valuing projects with two-state variables. Monte Carlo 
is a significant substitute to value European and American options that have one or more state variables.

Table 4: Suitable option valuation methods for option types and number of variables (Nembhard et. al. 2002)

\begin{tabular}{|c|c|c|}
\cline { 2 - 3 } \multicolumn{1}{c|}{} & One variable & Two variables \\
\hline European & $\begin{array}{c}\text { Black-Scholes Equation } \\
\text { Binomial Lattice } \\
\text { Monte Carlo Simulation }\end{array}$ & $\begin{array}{c}\text { Pentanomial Lattice } \\
\text { Monte Carlo Simulation }\end{array}$ \\
\hline American & $\begin{array}{c}\text { Binomial Lattice } \\
\text { Monte Carlo Simulation }\end{array}$ & $\begin{array}{c}\text { Pentanomial Lattice } \\
\text { Monte Carlo Simulation }\end{array}$ \\
\hline
\end{tabular}

\subsubsection{Black Scholes Formula}

The Black Scholes model was developed by Fischer Black and Myron Scholes in 1973. The Black Scholes formula provides the price of European options. It is extensively used with certain adjustments and corrections by the participants of the options markets. The concept of this model is based on hedging the option by purchasing and selling a particular asset in the appropriate manner, hence eliminating the risk. The assumptions of the model have been generalized and modified to meet various objectives. This has contributed to the development of a large number of models presently used in risk management and derivative pricing.

Consider a European call option is valued with Black-Scholes pricing equation for the variable asset price Sand the time till expiry $T$, has an exercise price set to unity. The Black-Scholes formula is derived from this equation by solving for the consequent terminal and boundary 
conditions. The formula is used to determine the price of European call and put options. The call option, regarding the Black-Scholes criteria (for a non-dividend paying underlying stock) is valued as:

$$
\begin{gathered}
C_{E}(S, t)=N\left(d_{1}\right) S-N\left(d_{2}\right) K_{E} e^{-r(T-t)} \\
d_{1}=\frac{1}{\sigma_{E} \sqrt{T-t}}\left[\ln \left(\frac{S}{K_{E}}\right)+\left(r+\frac{\sigma_{E}^{2}}{2}\right)(T-t)\right] \\
d_{2}=\frac{1}{\sigma_{E} \sqrt{T-t}}\left[\ln \left(\frac{S}{K_{E}}\right)+\left(r-\frac{\sigma_{E}^{2}}{2}\right)(T-t)\right] \\
=d_{1}-\sigma_{E} \sqrt{T-t}
\end{gathered}
$$

The price of the correspondent put option is:

$$
\begin{gathered}
P_{E}(S, t)=K_{E} e^{-r(T-t)}-S+C_{E}(S, t) \\
P_{E}(S, t)=N\left(-d_{2}\right) K_{E} e^{-r(T-t)}-N\left(-d_{1}\right) S
\end{gathered}
$$

Here $N($.$) represents the cumulative distribution function of the standard normal distribution,$ $T$ - $t$ shows the time to maturity, $K_{E}$ stands for the exercise price, $S$ symbolizes the spot price of the underlying asset, $\sigma_{E}$ denotes the volatility of returns of the underlying asset and $r$ serves as the risk free rate.

\subsubsection{Monte Carlo Simulation}

The Monte Carlo methods are a wide range of computational algorithms based on the repetitive random sampling to achieve numerical results. Monte Carlo methods can be used to 
solve problems that have probabilistic interpretation. In real options, these are used by financial analysts for creating stochastic financial models instead of the conventional static and deterministic models. The simulation models can be employed to get various potential routes of progress since existing date to the final date of option for the underlying state variables. Monte Carlo simulation method generates sample path to determine the maximum profit on each path.

$$
d X=\mu X d t+\sigma X d z
$$

We assume that the above equation is the process pursued by an underlying variable $X$ in a risk-neutral world and $z$ represents the Weiner process, $\mu$ is the expected return and $\sigma$ is the volatility. We then break down the lifespan of the underlying variable in $N$ small intervals of length $\Delta t$ for simulation of the path pursued by $X$, thus the above equation can be expressed as;

$$
X(t+\Delta t)-X(t)=\mu X(t) \Delta t+\sigma X(t) \varepsilon \sqrt{\Delta t}
$$

Here $X(t)$ represents the value of $X$ at time $t$ and $\varepsilon$ is the random sample taken from a normal distribution with unit standard deviation and a mean of zero. This facilitates to evaluate the value of $X$ at time $\Delta t$ from the basic value of $X$ at time zero and the value at time $2 \Delta t$ from the value at time $\Delta t$ and this continues. This equation is true only in the case that $\Delta t$ tends to zero. One simulation trial comprises of building an entire path for $X$ with $N$ random samples from a normal distribution. Equation (2.5) is used to create a path for $X$ and is true for all $\Delta t$. 


\subsubsection{Lattice Approach}

The lattice model is an approach employed for the valuation of options where a discretized model is needed. The pricing of an American option is a representative example for equity options, where a decision for exercising of the option is needed any time prior to and during maturity. However, a continuous model like Black Scholes model will only allow for the valuation of European options, where the option can be exercised at its maturity date. The lattices are additionally significant for use in the interest rate derivatives as they deal with many of the problems confronted with continuous models.

The lattice methodology generally involves dividing of time between now and the expiration of option in $N$ discrete periods. At a particular time $t$, the model has a certain number of outputs at time $t+1$ in a way that each potential change in the status of the world between $\mathrm{t}$ and $t+1$ is confined in a branch. This method is followed by subsequent iterations until mapping of every possible path between $t=0$ and $t=N$ is achieved. Then the probabilities for each $t$ to $t+1$ path are estimated. The results and probabilities are assessed backwards throughout the tree to finally determine a reasonable value of the option for the current day. As discussed above, the lattice technique is effective in valuing American options where the decision of exercising the option can be modeled at every discrete time and price combination. This is why the real options are frequently modeled using a lattice framework with customized assumptions.

The binomial options pricing model is the basic lattice model and the standard (canonical) procedure was suggested by Cox et. al. (1979). More than 20 different methods have been 
developed; each of them derived under a variety of assumptions regarding the development of the underlying price. With the increase in the number of time-steps (within limit), these methods converge to log-normal distribution and finally produce the same option price as Black Scholes. Additional enhancements are created to gain stability comparative to BlackScholes with the variation in the number of time-steps. The recent models are actually created around downright convergence to Black-Scholes (Ganikhodjaev and Bayram 2012).

The trinomial tree designed by Phelim Boyle (1986) is a variation on the binomial where valuation is dependent on the option values at the up, down and middle nodes in the subsequent time-step (Yuen and Yang 2010). There is a similar but smaller range of methods that exist for binomial trees. The trinomial model is known to show more accurate results than the binomial model when lesser time-steps are involved and is consequently used when the resources or computational speed may be a concern. 


\section{Chapter 3}

\section{Model}

\subsection{Applying Financial Models for Quality Control}

This study is based on an options valuation model for using one of the two control charts with different levels of strictness of quality standards. The option values of using each of these control charts are determined with the objective of maximizing the profits while considering the market variables of price and the number of sales.

This section covers the derivation of financial models of this project. The product price and the number of sales are the two main factors that make up the product revenue. The number of sales is a state variable $S_{1}(t)$ that shows the amount of product sales for a time period which begins at time $t$. The product price during the time period that begins at time $t$ is another variable denoted by $S_{2}(t)$. Thus the product sales revenue for a time period starting at time $\mathrm{t}$ would be;

$$
R(t)=S_{1}(t) S_{2}(t)
$$

The number of sales of the product is supposed to be equal to the quantity of units produced during each time period. The fixed production cost for a time period is assumed to be $\mathrm{F}$ and 
the variable production cost for each unit of the product is denoted by $V$. The aim is to create a profit function for two different control charts; Chart 1 with less strict quality standards and Chart 2 with relatively more strict standards and higher implementation cost. One of these two charts that come up with higher profits would be referred for use. In order to justify the benefit of applying one chart over the other, the variable $g$ is employed to represent the defect rate (percentage loss) achieved as a consequence of using a control chart. Let $g_{1}$ is a loss that results from applying control Chart 1 and $g_{2}$ is the loss that occurs as of applying control Chart 2. Then, the profit per time period when one of the two control Charts is used can be given as;

$$
\begin{aligned}
& \Gamma_{1}(t)=\left(1-g_{1}\right) S_{1}(t) S_{2}(t)-\left[F+V S_{1}(t)\right]-\left[K_{1}+V_{1} S_{1}(t)\right] \text { with Chart } 1 \\
& \Gamma_{2}(t)=\left(1-g_{2}\right) S_{1}(t) S_{2}(t)-\left[F+V S_{1}(t)\right]-\left[K_{2}+V_{2} S_{1}(t)\right] \text { with Chart } 2
\end{aligned}
$$

where $\Gamma(t)$ denotes the total profit, $K_{1}$ and $K_{2}$ are the fixed costs and $V_{1}$ and $V_{2}$ are the variable costs of using control Charts 1 and 2 respectively, $g_{1}>g_{2}, K_{1}<K_{2}$ and $V_{1}<V_{2}$. The $g_{1}>g_{2}$ and $g_{1}$ refers to Chart 1 which is less strict than Chart 2 so the loss that results with the use of Chart 1 is greater than that of applying Chart 2. Similarly $K_{1}<K_{2}$ and $V_{1}<V_{2}$ because Chart 1 is less strict and incurs lesser fixed and variable costs as compared to the costs of Chart 2. Equations (3.2) and (3.3) show the relationship among the number of sales, price, effect of using a control chart, fixed and variable costs of product and the resulting profit. The option value is computed by calculating the difference in profits; the profit gain, that might occur due to the use of two different control charts. We decide which one of the two charts is 
favourable for use depending on the option value. The profit gain is the difference between equations (3.2) and (3.3), which reduces to

$$
\Gamma_{2}(t)-\Gamma_{1}(t)=\left(g_{1}-g_{2}\right) S_{1}(t) S_{2}(t)-\left[\left(K_{2}-K_{1}\right)+\left(V_{2}-V_{1}\right) S_{1}(t)\right]
$$

If $\Gamma_{2}(t)-\Gamma_{1}(t)>0$, the use of Chart 2 is recommended. The control Chart 1 may be preferable in case the difference is less than zero.

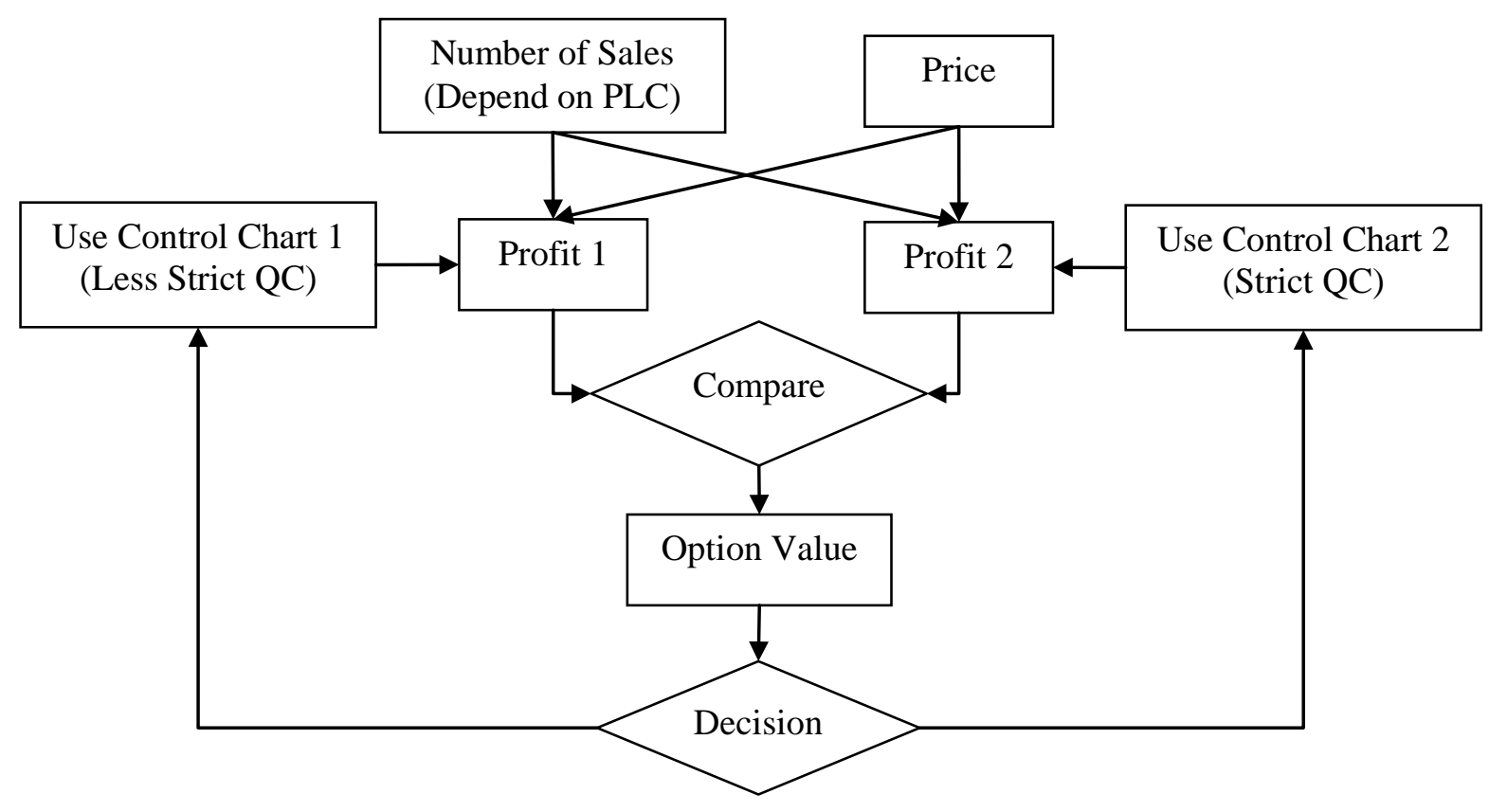

Figure 1. Relation between variables, option value, control charts effects and the decision. 


\subsection{Demand with PLC and Price}

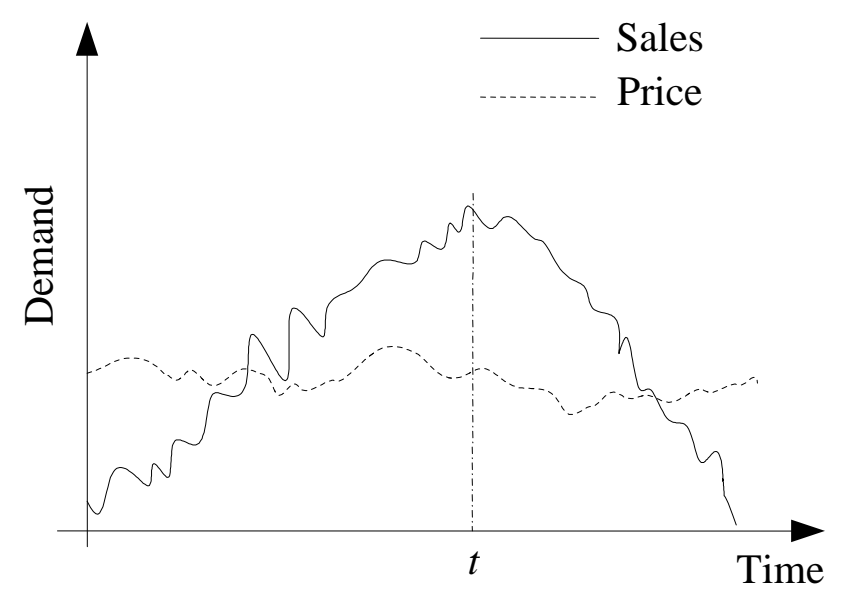

Figure 1. The demand regimes in relation with price

The product demand is supposed to follow a Geometric Brownian motion in this model as shown in Figure 1. The two variables are correlated and separated in two phases of PLC; the growth regime and the decay regime (Table 2). The correlation between two demand regimes is given in Table 3. The regime switching of the demand is a cumulative normal distribution from the time when the product is introduced in the market with mean represented by $\mu$ and standard deviation denoted by $\sigma$.

Table 5. The demand regimes

\begin{tabular}{|c|c|c|}
\cline { 2 - 3 } \multicolumn{1}{c|}{} & Growth Regime $\left(\mathrm{A}_{\mathrm{g}}\right)$ & Decay Regime $\left(\mathrm{A}_{\mathrm{d}}\right)$ \\
\hline Sales & $\left(\mu_{g}, \sigma_{g}\right)$ & $\left(\mu_{d}, \sigma_{d}\right)$ \\
\hline Price (B) & \multicolumn{2}{|c|}{$\left(\mu_{p}, \sigma_{p}\right)$} \\
\hline
\end{tabular}


Table 6. Correlation between demands

\begin{tabular}{|l|c|c|}
\cline { 2 - 3 } \multicolumn{1}{c|}{} & Growth regime and price & Decay regime and price \\
\hline Correlation & $\rho_{1}$ & $\rho_{2}$ \\
\hline
\end{tabular}

\subsection{Lattice Construction}

We have a correlated demand for a product with two demand regimes and the product price. The combined regimes are discretized by a three dimensional pentanomial lattice that results in positive conditional branch possibilities. This concept has been derived from Wahab (2006).

\subsection{Valuation of the Project}

The projects can finally be valued by using the lattice approach as formulated in previous section. The valuation of an options framework initiating from the terminal nodes, reels back repetitively towards the lattice origin. The project value at each terminal node is the final cash flow depending upon demand and corresponding price of the product at the earlier time period. The project value at the intermediate nodes is a sum of the current and discounted expected project values. The possibility of regime switching in the subsequent period is also considered as the expectation is determined. The project value is the value at the origin node of the lattice known as the discounted expected project value (Wahab, Lee and Park 2011). 
In order to explain the backward repetitive function, let NPV of the project depending upon demand for a product with demand $A$ and price $B$ in a combined regime $P$ and time step $t$. Here $P$ can be $\left(A_{\mathrm{g}}, B\right)$ or $\left(A_{\mathrm{d}}, B\right)$; and for example the corresponding demands and prices for the regime $\left(A_{g}, B\right)$ will be $S_{1 g t}^{A}$ and $S_{2 t}^{B}$ respectively. The probability of a product for switching from growth to decay at time $t$ is assumed to be $p(t)$ and the optimal profit by the product in period $t$ is denoted by $\pi_{t}$. Hence, the NPV of this project is represented as $\operatorname{NPV}\left(S_{1 P t}^{A}, S_{2 P t}^{B}, P, t\right)$ and the discounted expected future value as $N P V\left(S_{1 P, t+1}^{A}\right.$, $\left.S_{2 P, t+1}^{B}, P, t\right)$. In this way, the NPV can be maximized by exploring all potential combinations. That is,

$$
N P V\left(S_{1 P t}^{A}, S_{2 P t}^{B}, P, t\right)=\max \left\{\pi_{t}\left(S_{1 P t}^{A}\right)+E V\left[S_{1 P, t+1}^{A}, P, t\right]\right\}
$$

For the combined regime $\left(\mathrm{A}_{\mathrm{g}}, \mathrm{B}\right)$,

$$
\begin{aligned}
& E V\left(S_{1 g, t+1}^{A}, S_{2, t+1}^{B},\left(A_{g}, B\right), t\right)= \\
& e^{-r t}\left\{(1-p(t)) E\left[N P V\left(S_{1 g, t+1}^{A}, S_{2, t+1}^{B},\left(A_{g}, B\right), t+1\right)\right]\right. \\
& \left.+p(t) E\left[N P V\left(S_{1 d, t+1}^{A}, S_{2, t+1}^{B},\left(A_{d}, B\right), t+1\right)\right]\right\}
\end{aligned}
$$

and when the current combined regime is $\left(A_{d}, B\right)$,

$$
\begin{aligned}
& E V\left(S_{1 d, t+1}^{A}, S_{2, t+1}^{B},\left(A_{d}, B\right), t\right)= \\
& \quad e^{-r t}\left\{E\left[N P V\left(S_{1 d, t+1}^{A}, S_{2, t+1}^{B},\left(A_{d}, B\right), t+1\right)\right]\right\}
\end{aligned}
$$


The $E[N P V(., \ldots, \ldots, .)$.$] is determined as a product of the conditional branch probabilities$ and their related NPV. A backward dynamic programming technique is applied that begins at the final layer and reels backwards to the lattice origin. The discounted expected value of a project can be determined at the root node for every potential combined regime. 


\section{Chapter 4}

\section{Numerical Examples}

\subsection{Problem Data}

A product has a demand $\left(S_{1}\right) 10,000$ and the price $\left(S_{2}\right)$ of $\$ 10$. The life cycle of the product is estimated to be five years. The mean values of growth $\left(\mu_{\mathrm{g}}\right)$, decline $\left(\mu_{\mathrm{d}}\right)$ and price $\left(\mu_{\mathrm{p}}\right)$, during the product life cycle are $0.3,-0.25$ and 0.06 respectively and the volatilities for growth $\left(\sigma_{\mathrm{g}}\right)$, decline $\left(\sigma_{\mathrm{d}}\right)$ and price $\left(\sigma_{\mathrm{p}}\right)$ are $0.4,0.15$ and 0.1 respectively. The correlation $\left(\rho_{1}\right)$ for growth and price is 0.11 and the correlation $\left(\rho_{2}\right)$ for decay and price is 0.2 . The fixed cost $\left(K_{1}\right)$ incurred with the use of control Chart 1 is $\$ 300$ and the variable cost $\left(V_{1}\right)$ is $\$ 0.9$. The fixed cost $\left(K_{2}\right)$ applied with the implementation of Chart 2 is $\$ 500$ and the variable cost $\left(V_{2}\right)$ is $\$ 1.1$. The defect rate $\left(g_{1}\right)$ achieved with use of chart 1 is 0.07 and with the implementation of Chart $2\left(g_{2}\right)$ is 0.01 . The resultant profit gain is $\$ 215872$ and this concludes that according to Equation (3.4), the implementation of control Chart 2 is more profitable.

\subsection{Results}

Figures 2-13 illustrate the sensitivity analysis of mean, volatility, correlation factors, demand, price, defect rates and fixed costs regarding the profit gain. These figures show how 
the profit gain varies when these factors are individually changed throughout a range while the rest of the variables are constant. This analysis helps in decision making as there are certain ranges that suggest the maximum benefit of using one control chart over the other.

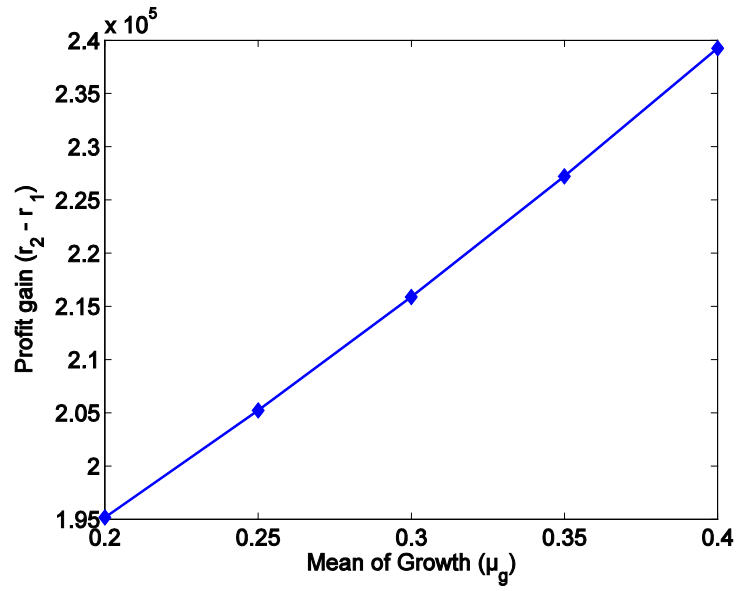

Figure 2. Mean of growth regime versus profit gain

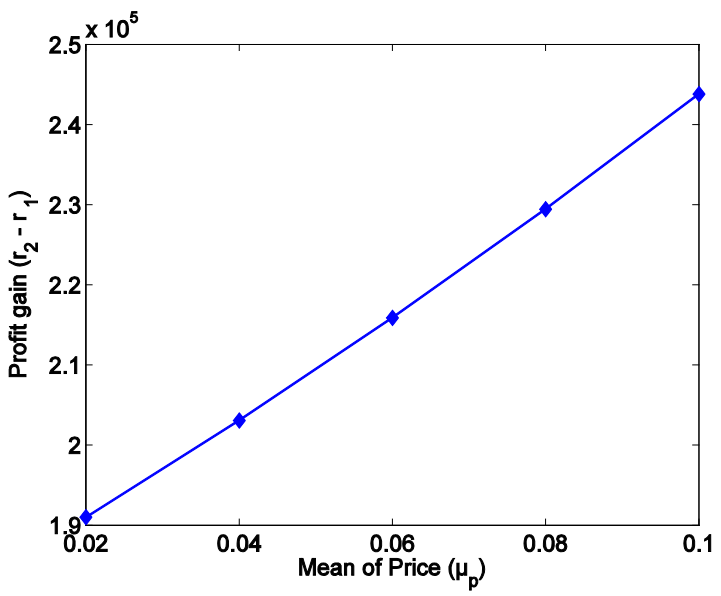

Figure 4. Mean of price versus profit gain

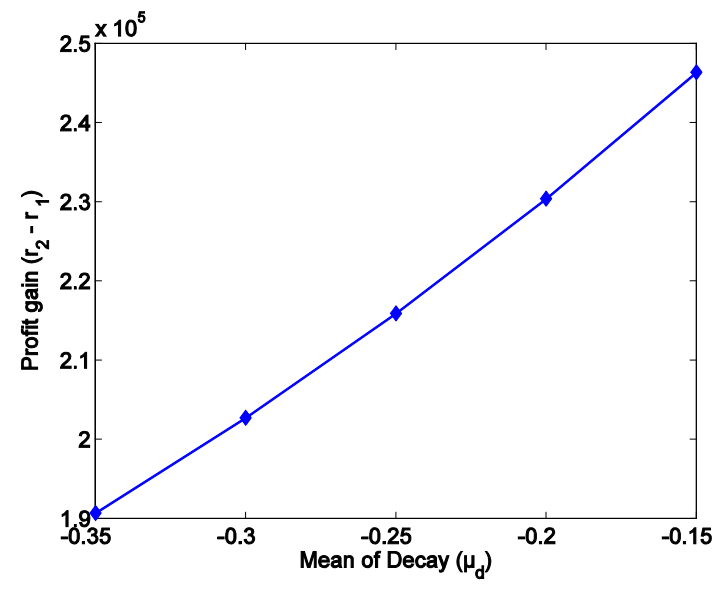

Figure 3. Mean of decay regime versus profit gain

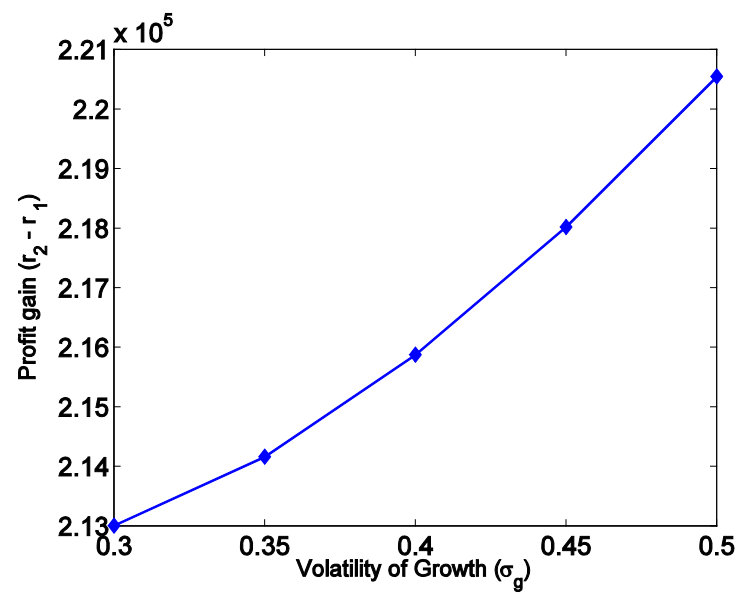

Figure 5. Volatility of growth regime versus profit gain 


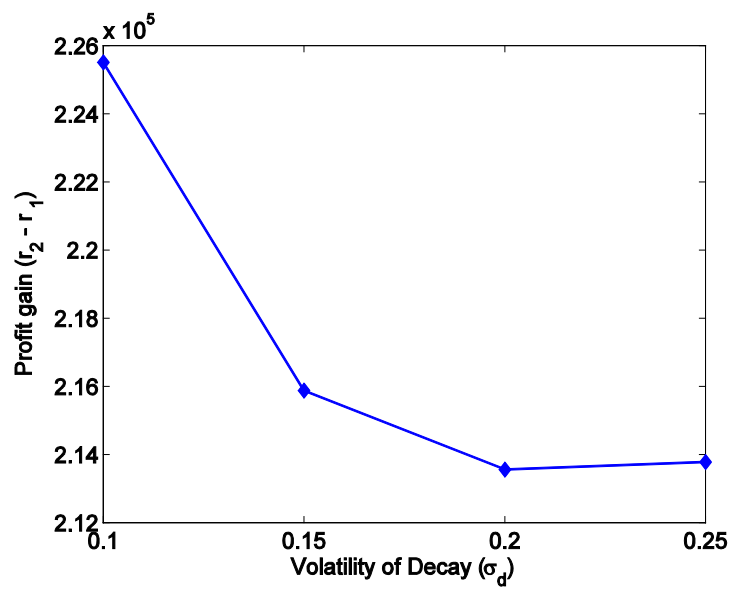

Figure 6. Volatility of decay regime versus profit gain

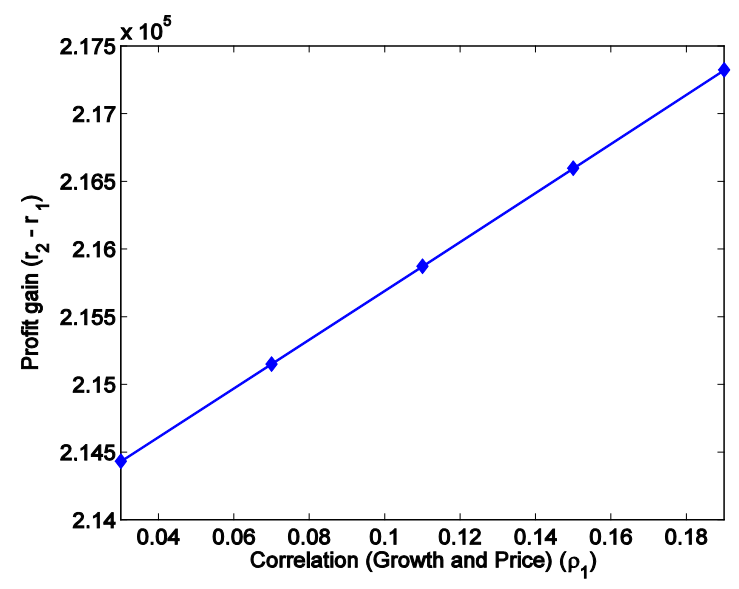

Figure 8. Correlation factor of decay and price versus profit gain

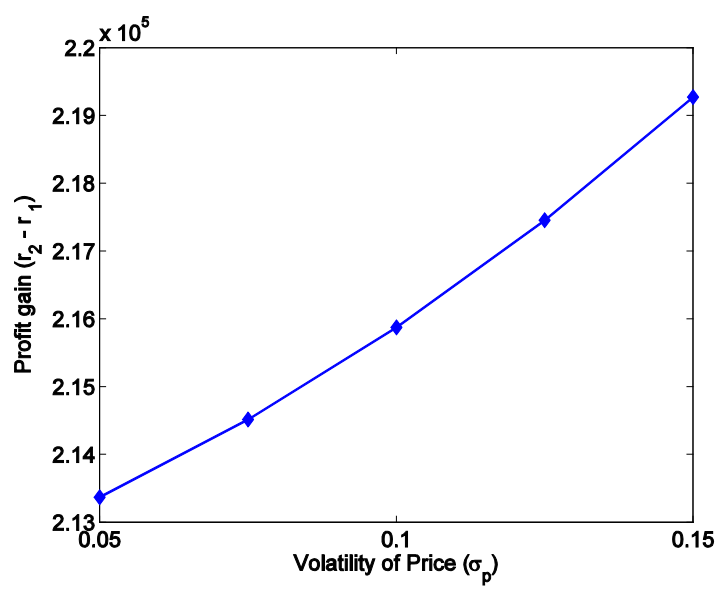

Figure 7. Volatility of price versus profit gain

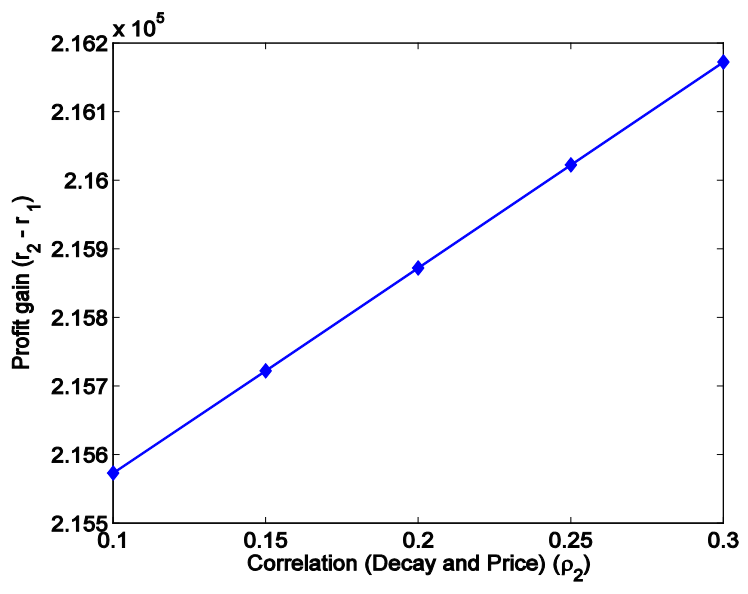

Figure 9. Correlation factor of growth and price versus profit gain 


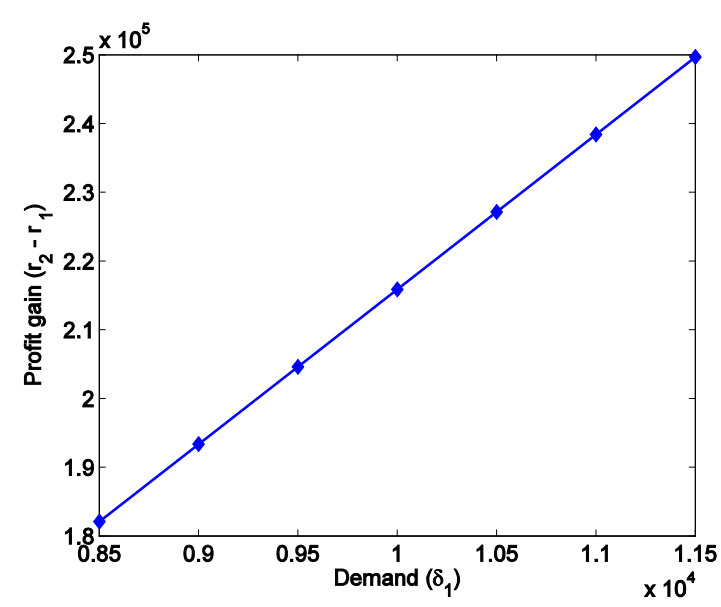

Figure 10. Product demand versus profit gain

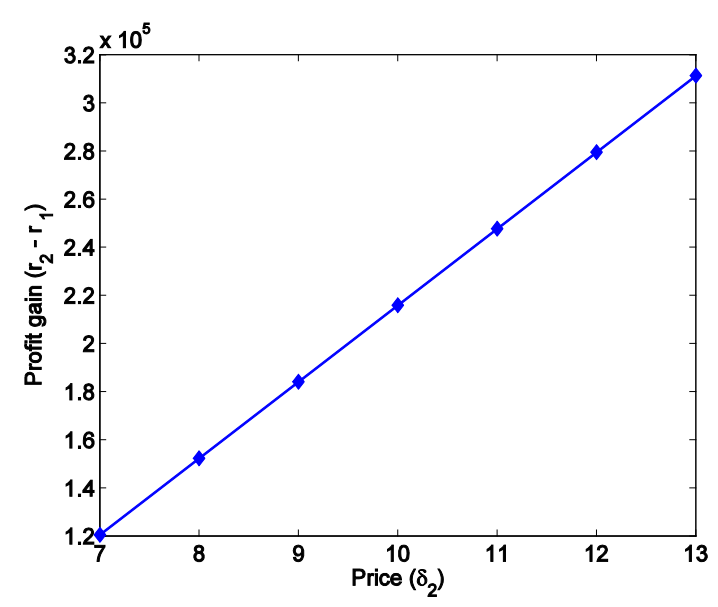

Figure 11. Product price versus profit gain

Figure 12 proposes that the profit gain is maximum when the difference between the defect rates $\left(g_{1}-g_{2}\right)$ is maximum. More difference in defect rates means a higher variation in standards that would result in a larger profit gain. Hence more benefit will be derived from applying Chart 2 when the defect rate due to Chart $1\left(g_{1}\right)$ is higher. Similarly, Figure 13 suggests that the control Chart 2 is recommended when the difference between the fixed costs $\left(K_{1}-K_{2}\right)$ is maximum and the maximum advantage of using Chart 2 over Chart 1 is acheived when the fixed cost of Chart 1 is relatively higher than that of Chart 2.

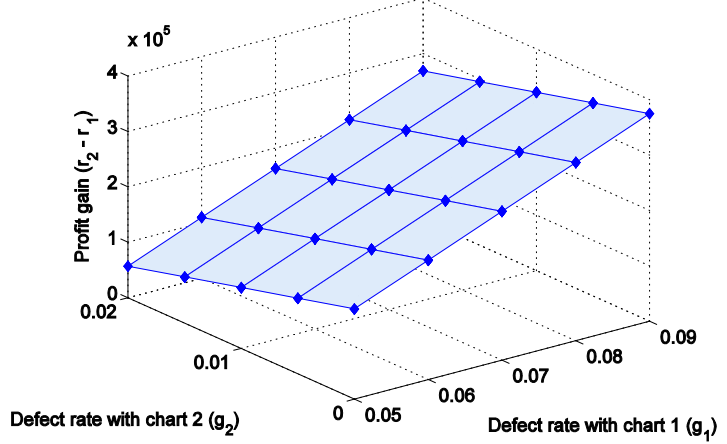

Figure 12. Defect rates $g_{1}$ and $g_{2}$ versus profit gain

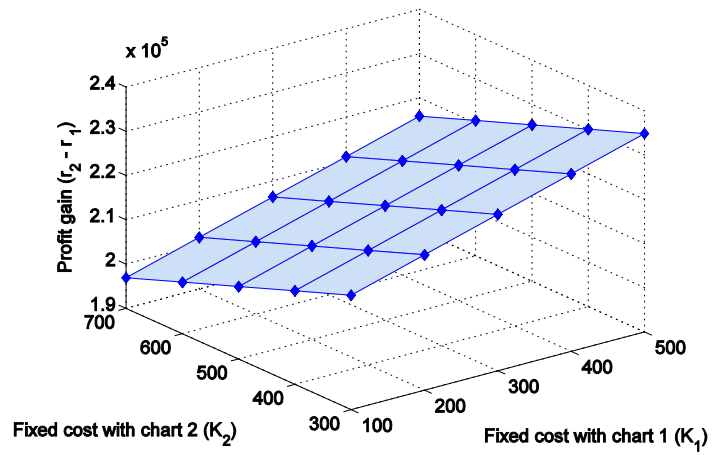

Figure 13. Fixed costs $K_{1}$ and $K_{2}$ versus profit gain 
The results of the experimental data identify the appropriate control chart for the product. The resultant profit gain confirms that the control Chart 2; one of the two potentially applicable quality standards, is a preferred choice. The higher the profit gain, the more is the option value of switching from Chart 1 to Chart 2.

The sensitivity analysis to the results shows that the profit gain increases with rise in mean values of product price and the growth and decay phases of demand. A positive trend of profit gain is observed with the increase in volatility of price and of the growth phase of demand, but the volatility of decay phase of demand shows an inverse trend with profit gain. This means that, higher the volatility of demand in decline phase, lower will be the profit gain from switching to a new control chart. The product demand, price and the correlation factors show a direct relation with the profit gain. Furthermore, the maximum benefit is achieved by using control Chart 2 instead of Chart 1 when the defect rate and the fixed cost incurred by applying control Chart 2 is much lower than those by using control Chart 1 . 


\section{Chapter 5}

\section{Conclusion}

The manufacturing systems produce a variety of products and each of them has a certain lifespan. A product generally shows variability in its demand growth which affects the systems of its manufacturing facility. Most of the existing economic quality control procedures do not account for the demand dynamics of a product in relation with price. The effectiveness of a control chart varies with the change in these parameters and can be judged by the profitability in terms of the quality control decision. An industry scenario has been created in this project to validate the significance of real options in valuing the quality control chart decisions.

This study shows how the option value of selecting one out of the two potential quality control charts can be evaluated with a real options approach. A tool has been developed to justify the effectiveness of a new prospective quality control chart in comparison with the existing control chart. The option values were computed with the lattice approach and a dynamic programming model used to determine the NPVs. The profit gain in this case gives the value of switching from one control chart to the other. These results and the sensitivity analysis will help decision makers to understand the characteristic values of options. 
When suitable, the switching of a manufacturing system to more strict quality standards presents extended benefits of better reputation of the firm in terms of product quality. The future studies may investigate the values of switching points of prospective control charts at certain levels of demand throughout the product life cycle. 


\section{References}

Bass, F. M. (1969). A new product growth for model consumer durables. Management Science, 15(5): 215-227.

Birou, L., Fawcett, S. E., and Magnan, G. M. (1998). The product life cycle: A tool for functional strategic alignment. International Journal of Purchasing and Materials Management, 34(2): 37-51.

Birou, L., Fawcett, S. E., and Magnan, G. M. (1997). Integrating product life cycle and purchasing strategies. International Journal of Purchasing and Materials Management, 33(1): 23-31.

Black, F. and Scholes, M. (1973). The pricing of options and corporate liabilities. Journal of Political Economy, 81(3): 637-654

Bollen, N. P. B. (1998). Valuing option in regime-switching models. Journal of Derivatives, 6:38-49

Bollen, N. P. B. (1999). Real Options and Product Life Cycles. Management Science, 45(5): $670-684$

Boyle, P. P., Evnine, J. and Gibbs, S. (1989). Numerical evaluation of multivariate contingent claims. The Review of Financial Studies, 2(2): 241-250

Chenavaz, R. (2012). Dynamic pricing, product and process innovation. European Journal of Operational Research, 222(3): 553-557

Cox, J. C., Ross, S. A. and Rubinstein, M. (1979). Option pricing: A simplified approach. Journal of Financial Economics, 7(3): 229-263 
Deming, W. E. (1986). Out of the Crisis. Massachusetts Institute of Technology, Center for Advanced Engineering Studies, Cambridge, MA.

Dolgui, A. and Proth, J. M. (2010). Pricing strategies and models. Annual Reviews in Control, 34(1): 101-110

Feigenbaum, A. V. (1956). Harvard Business Review.

Ganikhodjaev, N. and Bayram, K. (2012). Random Binomial Tree Models and Options. Journal of Applied Sciences, 12(18):1978-1981

Gherasim A. (2011). Product Life Cycle Approach. Economy Transdisciplinarity Cognition, 15(2): 158-167

Golder, P. N. and Tellis G.J. (2004). Growing, Growing, Gone: Cascades, Diffusion, and Turning Points in the Product Life Cycle. Marketing Science, 23(2): 207-218

He, H. and Pindyck, R. (1992). Investment in flexible production capacity. Journal of Economic Dynamics and Control, 16(3-4): 575-599

Huang, M. G. (2009). Real options approach-based demand forecasting method for a range of products with highly volatile and correlated demand. European Journal of Operational Research, 198(3): 867-877

Hull, J. C. (2005). Fundamentals of futures and options markets (5 ${ }^{\text {th }}$ edition), chapter 8. Pearson Education Inc. published. Upper Saddle River, New Jersey, 07458.

Johansson, M., Hallberg, N., Hinterhuber, A., Zbaracki, M. and Liozu, S. (2011). Pricing strategies and pricing capabilities. Journal of Revenue and Pricing Management, 11(1): 411

Kamrad, B. and Ritchken, P. (1991). Multinomial approximating models for options with k state variables. Management Science, 37(12): 1640-1653 
Tsekouras, K., Dimara, E. and Skuras, D. (2002). Adoption of a quality assurance scheme and its effect on firm performance: A study of Greek firms implementing ISO 9000.Total Quality Management, 13:6, 827-841

Kale, S. S. (2014). Quality assurance and quality control of pressure relief systems. Process Safety Progress, 33(2): 136-142

Lambertini, L. and Mantovani, A. (2010). Process and product innovation: A differential game approach to product life cycle. International Journal of Economic Theory, 6(2): 227-252

Law, A. M. and Kelton, W. D. (2000). Simulation Modeling and Analysis (Third edition), McGraw-Hill, New York.

McCarthy, E. J., Shapiro, S. J. and Perreault, W. D. (1994)a. Basic Marketing (7 ${ }^{\text {th }}$ Canadian edition), chapter 10, Richard D. Irwin Inc. published. Burr Ridge, Illinois, Boston, Massachusetts and Sydney, Australia.

McCarthy, E. J., Shapiro, S. J. and Perreault, W. D. (1994)b. Basic Marketing (7 $^{\text {th }}$ Canadian edition), chapter 18, Richard D. Irwin Inc. published. Burr Ridge, Illinois, Boston, Massachusetts and Sydney, Australia.

McDonald, R. and Siegel, D. (1986). The value of waiting to invest. The Quarterly Journal of Economics, 101(4): 707-727

Mihalcin, M. J., Mazzuchi, T. A., Sarkani, S. and Dever, J. R. (2014). Quality Control—An Approach Applying Multivariate Control Charts during the Operation of Systems Involving Human Processes. Systems Engineering, 17(2): 204-212

Milo, M. W., Roan, M. and Harris, B. (2015). A new statistical approach to automated quality control in manufacturing processes. Journal of Manufacturing Systems, 36: 159-167 
Mohammadi, M., Tavakoli, A. and Ebrahimi, A. (2014). Predicting product life cycle using fuzzy neural network. Management Science Letters, 4(9): 2057-2064

Nembhard, H. B., Shi, L. and Aktan, M. (2002). A real options design for quality control charts. The engineering economist, 47(1): 28-59

Nicholls, G. M., Lewis, N. A., Zhang, L. and Jiang, Z. (2014). Breakeven Volatility for Real Option Valuation. Engineering Management Journal, 26(2): 49-61.

Onkvisit, S. and Shaw, J. J. (1986). Competition and product management: Can the product life cycle help? Business Horizons, 29(4): 51-62

Orbach, Y. and Fruchter, G. E. (2014). Predicting product life cycle patterns. Marketing Letters, 25(1): 37-52

Pindyck, R. (1988). Irreversible investment, capacity choice and the value of the firm. The American Economic Review, 78(5): 969-985

Rothery, B. (1992) ISO 9000 (Aldershot, Gower).

Schiffauerova, A. and Thomson, V. (2006). A review of research on cost of quality models and best practices. International Journal of Quality and Reliability Management, 23(6): 647-669

Sommers, M. S., Barnes, J. G. and Stanton, W. J. (1998)a. Fundamentals of marketing (8 ${ }^{\text {th }}$ Canadian edition), chapter 10, McGraw-Hill Ryerson Limited published, Canada.

Sommers, M. S., Barnes, J. G. and Stanton, W. J. (1998)b. Fundamentals of marketing (8 ${ }^{\text {th }}$ Canadian edition), chapter 14, McGraw-Hill Ryerson Limited published, Canada.

The Associated Press. (2014, September 26). Ford recalls 850,000 cars and SUVs in North America. Thestar.com (Business). Retrieved from http://www.thestar.com 
Thimm, G., Lee, S. G. and Ma, Y. S. (2006). Towards unified modelling of product lifecycles. Computers in industry, 57(4): 331-341

Triantis, A. J. and Hodder, J. (1990). Valuing flexibility as a complex option. The Journal of Finance, 45(2): 549-565

Tyagi, S., Cai, X. and Yang, K.(2015). Product life-cycle cost estimation: a focus on the multi-generation manufacturing-based product. Research in Engineering Design, 26(3): 277-288

Vloeberghs, D. and Bellens, J. (1996). ISO 9000 in Belgium: experience of Belgian quality managers and HRM. European Management Journal, 14(2): 207- 211.

Wagner, S. F., Padhi, S. S. and Zanger, I. (2014). A real option-based supply chain project evaluation and scheduling method. International Journal of Production Research, 52(12): 3725-3743.

Wahab, M. I. M. (2006). A real options approach to the valuation of manufacturing flexibility with two state variables and regime switching. Theasis, Department of Mechanical and Industrial Engineering, University of Toronto, Toronto, Canada.

White, G.R.T., Samson, P., Rowland-Jones, R. and Thomas, A.J. (2009). The implementation of a quality management system in the not-for-profit sector. The TQM Journal, 21(3) 273 283

Yeoman, Dr. I. (2007). Pricing. Journal of Revenue and Pricing Management, 6(1): 1-1

Yuen, F. L. and Yang, H. (2010). Option pricing with regime switching by trinomial tree method. Journal of Computational and Applied Mathematics, 233(8): 1821-1833 